Article

\title{
Unpacking Water Governance: A Framework for Practitioners
}

\author{
Alejandro Jiménez * ${ }^{*}$, Panchali Saikia ${ }^{\dagger}$, Ricard Giné ${ }^{\dagger}{ }^{\circledR}$, Pilar Avello, James Leten, \\ Birgitta Liss Lymer, Kerry Schneider and Robin Ward
}

Stockholm International Water Institute, 10055 Stockholm, Sweden; panchali.saikia@siwi.org (P.S.); ricard.gine@siwi.org (R.G.); pilar.avello@siwi.org (P.A.); james.leten@siwi.org (J.L.);

birgitta.liss.lymer@siwi.org (B.L.L.); kerry.schneider@siwi.org (K.S.); robin.ward@siwi.org (R.W.)

* Correspondence: alejandro.jimenez@siwi.org; Tel.: +46-8-121-360-41

† These authors contributed equally to this work.

Received: 25 November 2019; Accepted: 11 March 2020; Published: 15 March 2020

check for updates

\begin{abstract}
Water governance has emerged as an important topic in the international arena and is acknowledged to be a crucial factor for adequate and sustained progress towards achieving Sustainable Development Goal (SDG) 6. However, there is not enough clarity about the practical meaning of the term "water governance" and how to work with it. This paper reviews the term's use, to reveal how the concept is understood, referred to, and implemented in practice by different stakeholders. Based on literature review and consultations with experts, we identify and describe the core components of water governance (functions), describe their potential qualities when performed (attributes), and how they interrelate with the values and aspirations of the different stakeholders to achieve certain outcomes. These different components are described in detail to construct an operational framework to assess and work with water governance, which covers water and sanitation services delivery, water resources management and transboundary waters. This paper's findings provide practical guidance for decision makers and practitioners on how action-oriented water governance processes can be meaningfully designed, and ultimately, how to strengthen efforts aiming to improve water governance.
\end{abstract}

Keywords: water governance; good governance; adaptive governance; SDG 6; human rights to water and sanitation

\section{Introduction}

The world's water resources are increasingly under pressure with climate change only set to exacerbate the challenges ahead. It is now widely acknowledged that, at global to local scales, "the scarcity at the heart of the global water crisis is rooted in power, poverty and inequality, not in physical availability" [1-3]. In a dynamic and fast changing background-i.e., with continuous changes in political, legal, economic, social and technological aspects around water-it is important to ensure that efforts to improve water resources management and services offer the best long term prospects. In addition, it is equally important to focus on minimising the impact of disasters on water resources and services; and to strengthen the ability to adapt and cope in situations of disturbance, external challenges and changes; to learn and self-organise, and to respond and recover quickly [4]. These objectives have garnered attention in terms of the concepts of sustainable development (Appendix A1) and resilience (Appendix A2), be it the increasing interest in these concepts in the literature [5] or the embedding of these concepts in the Global 2030 Agenda of building sustainable, resilient and inclusive societies [6]. Global partnerships have also been established such as the Global Resilience Partnership, where public and private institutions/organisations have joined hands to build a resilient, sustainable 
and prosperous future for vulnerable people and places. The Intergovernmental Panel on Climate Change has also emphasised promoting the need to build climate resilient pathways for a sustainable future [7]. In the water domain, resilience is a relatively new concept. A Vision 2030 study carried out jointly by the World Health Organisation and Department for International Development highlights that to cope with climate variability, resilience must be integrated in management [8]. The Global Commission on Adaptation, a global platform established in 2019, calls for accelerating climate change adaptation action in water and water-related sectors through a resilience approach [7].

With the increasing relevance of the concepts of sustainable development and resilience, the approaches to how water resources and services are managed and governed have seen a significant shift over the years. The engineering- and technology-driven management approaches are currently being scrutinised, and more integrated approaches emphasising good governance have emerged [1,9-11]. Governance can be defined as "the process of decision-making and the process by which decisions are implemented (or not implemented)" [11]. In Graham et al. [12], governance is described as "the interactions among structures, processes and traditions that determine how power and responsibilities are exercised, how decisions are taken, and how citizens or other stakeholders have their say". The characteristics or the attributes of governance have also evolved from a state-centric and hierarchical problem-solving approach, to 'good' governance, promoting openness, efficiency, rule of law, justice, transparency, accountability, broad participation, decentralisation and deliberation [12]. The World Bank report entitled 'Governance and Development', sets out the definition of good governance as the manner in which power is exercised in the management of a country's economic and social resources for development [13]. There are other layers of governance attributes which have emerged recently, and these are described as the 'new governance' models, which are society-centric, multilevel, collaborative and market-based [14]. In the resilience discourse, adaptive governance, and its attributes, appears as the most common approach towards building resilience capacity [4,15-17]. Resilience scholars define adaptive governance as the ability to evolve, adapt or transform in a situation of change, through a range of interaction and actions that occurs between different actors in a social-ecological system (Appendix A3), in order to meet a desired state [15-17].

Governance is a prerequisite for improving water management [18]. Water governance appeared in the scientific literature with the evolving nature of natural resources management approaches. Pahl-Wostl [18] provides a clear distinction between the two, where water management is described as the activities to analyse and monitor resources along with measures developed and implemented to keep the resources within a desirable condition, and water governance as a social function that helps regulate development and management of the water resources and services along with providing guidance towards a desirable state and away from an undesirable state. The discussion around water governance also started appearing on global platforms. The Hague 2000 Ministerial Declaration called for ensuring good governance that will promote involvement of the public and inclusion of the interests of all stakeholders in the management of water resources [19]. The 2001 International Conference on Freshwater in Bonn [20] identified water governance as the first of three areas for priority action. The first UN World Water Development Report pointed out that the "world's water crisis is one of water governance, essentially caused by the ways we mismanage water" [1]. Subsequent reports continued to stress the fact that governance is central to the long term management of water resources and that there is a need to pay attention to, and support, governance processes [11]. The multistakeholder Water Governance Initiative, chaired by The Organisation for Economic Co-operation and Development (OECD), reinforces this concept through a set of water governance principles [21], which highlight that water resources management is often hindered due to governance gaps in policy, administration, coordination, funding, information, and accountability. In studies that map water governance in 17 OECD and 13 Latin America and Caribbean (LAC) countries [22,23], the OECD provides evidence of governance failures as a stumbling block in water policy design and implementation. For instance, $90 \%$ of the LAC countries surveyed reported that a weak accountability mechanism resulted in poor implementation in the sector. Information and accountability gaps in the water sector were highlighted 
in almost half of the OECD countries. Ménard et. al., in an analysis on policy implementation gaps in water services, points to overall governance gaps in countries as one of the most common barriers in water policy implementation [24], as shown by the slower pace of progress of countries affected by fragility, in terms of access to water and sanitation services [25]. Another implementation gap highlighted by the authors is related to the behaviours of stakeholders, which can result in elite capture, third party opportunism and corruption. It is in this context, that there is a need to lay the groundwork for a greater understanding of water governance processes and approaches.

In the last two decades, the definition of water governance has been disputed by practitioners and researchers alike. Different schools of thought have adopted and interpreted governance from different perspectives, and international forums and platforms have understood and used this term with different interests, and sometimes with conflicting objectives [26]. Water governance has been referred to both as a process and as an outcome, which gives rise to different usage of the term. Allan defines water governance systems as those that determine who gets what water, when and how, and who has the right to water and related services and their benefits [27]. His focus is on the outcome. Lautze et al., on the other hand, review various definitions of water governance [26] and conclude that (i) governance is consistently viewed as the processes involved in decision-making; (ii) the processes of decision-making take place through institutions (including mechanisms, systems and traditions); and (iii) the processes and institutions of decision-making involves multiple actors. In doing so, they relate governance to the processes and institutions involved in decision-making, and not to the outcomes of that decision-making [28]. Another consideration that has been discussed is the scope of actions to be included in the definition of water governance [29]. Some scholars include the full range of decisions made in managing water, from policy-setting to service delivery [30]; while others see it as comprising of only the higher-level decisions (governance) that establish the context for day-to-day, and applied, operational decision-making (management) [29]. Another important discussion centres on identifying principles of good governance [31]. This discussion focuses on how governance should be performed to have the best possible chance of achieving intended outcomes.

Hence, much work and different entry points and views have been developed regarding the meaning of the term water governance. This article lays out a framework for understanding and improving water governance. Specifically, we propose a practical definition of water governance, depicting the concept into "what" (the functions), "how" (the attributes), and "what for" (the outcomes): "Water governance is a combination of functions, performed with certain attributes, to achieve one or more desired outcomes, all shaped by the values and aspirations of individuals and organisations".

Throughout the paper, we describe the set of governance functions, attributes and outcomes based on the literature review and the different consultations held. The discussion focuses on two areas of water governance: water and sanitation services and water resources. Within this second area, however, we deal separately with transboundary water management (Appendix A4), as the scale demands a broader understanding of regional or basin-wide political contexts that are not typically at the forefront of resource management at any other scale. We then present the operational framework and show its validity, demonstrated through an illustrative example. Conclusions show the way forward for the further development and application of this framework.

\section{Methods}

This paper combines desk review and consultations with experts, as shown in Table 1. 
Table 1. Summary table of methods.

\begin{tabular}{|c|c|c|c|c|c|c|}
\hline \multirow[t]{2}{*}{ Method } & \multirow[t]{2}{*}{ Scope/Participants Objective } & \multicolumn{5}{|c|}{ Year - 201X } \\
\hline & & 5 & 6 & 7 & 8 & 9 \\
\hline $\begin{array}{l}\text { Literature review on functions, } \\
\text { based on assessment } \\
\text { frameworks }\end{array}$ & First proposal of functions & $X$ & & & & \\
\hline $\begin{array}{l}\text { Expert consultations on } \\
\text { functions }\end{array}$ & $\begin{array}{l}\text { Refine the proposed list of } \\
\text { functions with } 30 \text { experts through } \\
\text { workshop and } 20 \text { partner } \\
\text { organisations online }\end{array}$ & & $x$ & & & \\
\hline $\begin{array}{l}\text { Literature review of } \\
\text { organisations working with } \\
\text { governance: functions and } \\
\text { attributes }\end{array}$ & $\begin{array}{l}\text { First proposal of functions and } \\
\text { attributes, } 25 \text { organisations } \\
\text { reviewed }\end{array}$ & & & $x$ & & \\
\hline $\begin{array}{l}\text { Literature review on } \\
\text { governance attributes and } \\
\text { resilience }\end{array}$ & $\begin{array}{l}\text { Refine list of attributes, } 60 \text { articles } \\
\text { reviewed }\end{array}$ & & & $x$ & $x$ & \\
\hline $\begin{array}{l}\text { City consultations on functions } \\
\text { and attributes }\end{array}$ & $\begin{array}{l}\text { Refine the proposed list of } \\
\text { functions and attributes, } 700 \\
\text { people involved in five different } \\
\text { consultations }\end{array}$ & & & & $x$ & $x$ \\
\hline $\begin{array}{l}\text { Final consultation on the whole } \\
\text { framework }\end{array}$ & $\begin{array}{l}\text { Refine the framework, } 36 \text { experts } \\
\text { through workshop and written } \\
\text { input }\end{array}$ & & & & & $x$ \\
\hline
\end{tabular}

The first part of the desk review was targeted to practical frameworks used in the application and assessment of water governance. The aim of this review was to come up with an initial set of functions, focused on water and sanitation services. As a result, an initial selection of governance functions was published in a briefing paper, developed jointly with the United Nations Children's Fund (UNICEF) [32,33]. The list of functions was further discussed within an expert consultation, including 30 experts (Appendix A5). During this two-day workshop discussion, the initial list of functions was presented and discussed among the group. The feedback was used to refine the list of functions and the definitions. Subsequently, this refined list was also discussed and further refined by way of an online discussion through the Sanitation and Water for All (SWA) partnership [34], which then led to the agreed Building Blocks set of governance functions that the partnership uses as part of its framework.

The second part of the desk review was aimed at developing a combined list of functions and attributes. Three databases were reviewed to select global organisations working on water issues: (i) the World Bank database (Appendix A6) of water and sanitation organisations; (ii) the raptim list of NGOs working on water (Appendix A7), and (iii) the list of convening organisations of the 2017 Stockholm International Water Institute (SIWI) World Water Week. Those organisations that appeared in at least two of these lists were screened against two criteria: (i) relevant work on water governance, and (ii) the type of organisation. The screened list aimed to include organisations of a different nature (e.g., development banks, donors, multilateral agencies, nonprofit organisations, etc.) that actively contribute to improved water governance (e.g., organisations with specific water governance departments or institutions leading the implementation of water governance programmes). A final list of 25 organisations were purposively selected. For each organisation, the annual reports and other key documents and publications (e.g., strategy reports, technical reports, policy briefs) were compared for review. Search queries used in the websites consisted of combinations of keywords around three key areas: (1) water governance, (2) good governance, and (3) adaptive governance. Additional thematic searches were also conducted, focused on the UN principles on good governance [31]. The development of attributes was complemented with a third literature review, which focused on the attributes of good governance and resilient governance and was conducted using database searches (Table 2). 
Sixty articles were selected and screened for the review, based on the inclusion of a discussion about governance attributes.

Table 2. Keywords and syntax used for literature search for the resilience and governance study.

\begin{tabular}{lll}
\hline & Database Sources & Keyword Searches \\
\hline & & $\begin{array}{l}\text { \#1 resilience and governance, the concept of resilience, linkages } \\
\text { of governance and resilience, how can governance help achieve } \\
\text { i. }\end{array} \quad$ Open access journals in JSTOR \\
ii. $\quad$ MDPI Sustainability journal & $\begin{array}{l}\text { manage resilience, etc. } \\
\text { iii. } \quad \text { Ecology and Society journal }\end{array}$ \\
iv. $\quad$ Taylor and Francis Online & $\begin{array}{l}\text { \#2 Through snowball method, where literature search results } \\
\text { from the first phase directed to the second stage search: } \\
\text { governance attributes and resilience, good governance and } \\
\text { resilience, adaptive governance and resilience, adaptive } \\
\text { governance theories and resilience, adaptive management and } \\
\end{array}$ \\
& resilience, adaptive governance attributes, polycentric \\
& governance and resilience, multilevel governance and resilience \\
\hline
\end{tabular}

The refined list of functions and attributes was presented and discussed during governance workshops in 2018 with around 700 different stakeholders in five cities, within the framework of a governance for resilience initiative, namely, SIWI and Arup's City Water Resilience Approach (CWRA) Programme [35]. Individual workshops were conducted in each city on governance and water resilience with the objective to discuss on the concepts and main attributes of resilient water governance in the urban context, along with understanding the governance challenges around currently faced shocks and stresses. The information gathered from these workshops and also from key informant interviews conducted with stakeholders in these cities helped structure and develop the diagnosis tools for assessing city water resilience. In addition to this, a three-day validation workshop called 'Global Knowledge Exchange' was held in London in August 2018, where city stakeholders and global experts gathered to validate the tools and discuss the correlation between resilience and water governance. This served to further refine the list of functions and attributes. As a final stage, the whole framework was reviewed by way of an expert consultation with 36 experts in water, sanitation and hygiene (WASH), water resources management (WRM) and transboundary water management (TWM) from SIWI. A working session was organised where the experts discussed the different elements of the framework and provided feedback. Written comments were also collected during a period of two weeks.

Based on these consultations, a final list of eight governance functions together with ten governance attributes are proposed. In addition, each function is defined and fine-tuned for three different areas: water resources management, water and sanitation services, and transboundary water management. Outcomes have been discussed and adapted using the Orders of Outcomes framework proposed by Olsen et al. [36] for achieving sustainable outcomes in source-to-sea systems. This framework has proven to be relevant for assessing progress in ecosystem governance [36-38]. It is also compatible with other frameworks used to understand the different type of outcomes that emerge from social processes [39-41].

\section{Results and Discussion}

Our proposed framework is a combination of governance functions, governance attributes, and governance outcomes, producing an easy-to-understand, easy-to-use operational framework on which practitioners can define their interventions. On this basis, the discussion is structured in six sections. First, we describe each of the eight core governance functions. Second, we fine-tune the definition of each function to suit the specificities of three different water areas: water and sanitation services delivery, water resources management or transboundary waters. Third, the discussion centres on identifying attributes for these functions, i.e., how they can be performed. Fourth, we introduce different types of 
outcomes [36]. Fifth, we analyse the linkages between governance functions, attributes and outcomes, through the values and aspirations, to construct the operational framework. Finally, we showcase the usefulness of the proposed conceptualisation of water governance through one practical application.

\subsection{The Core Governance Functions}

Core governance functions are the key processes performed, in various forms and to varying extents and quality, for the organised development and management of water resources and services. They include the main activities that the responsible organisations (typically a ministry, or basin authority) should undertake or facilitate, in cooperation with other stakeholders, to develop the sector. There are, however, blurred boundaries and linkages between the functions, and specific activities might be equally relevant to more than one function. For example, monitoring data serves as the basis for planning and budget allocation, and monitoring processes should also take into consideration the planning cycle. Hence, even if functions are hereinafter described separately, they are interlinked and form part of a system.

The functions are outlined below:

Policy and Strategy-Policymaking is the set of processes whereby laws, policies and strategies are developed, ratified and entered into force. This function comprises the set of norms, principles and priorities to achieve desired outcomes, as well as the set of rules, procedures, programs and/or mechanisms needed to achieve such ends. It provides the framework for links and interdependencies between water and other sectors (e.g., energy, agriculture, environment, land use, industry, navigation), harnessing synergies while managing potential conflicts. This function is increasingly important and takes on a new meaning with regard to transboundary water resources, where the regional scale demands the inclusion of foreign policy actors and state security strategists who are often more focused on issues related to sovereignty as opposed to focusing on water-centric problems and solutions.

Coordination-This function comprises the processes, mechanisms, instruments and platforms that promote and ensure multilevel, multisectorial, and multistakeholder cooperation among all actors-relevant ministries and departments of central, regional and local governments, civil society, academia, external support agencies and the private sector. It entails information sharing, dialogue and collaborative decision-making, linked to policy making and planning. At the transboundary scale, coordination over water resources management or development often falls under the umbrella of water diplomacy and can have far reaching impacts beyond the water sector, e.g., geopolitical security. Coordination is not a stand-alone process. It forms an important part of most governance functions, and specific coordination processes and mechanisms might be needed under particular circumstances (e.g., emergency or disaster response).

Planning and Preparedness-Planning is the process of data collection and analysis, formulation of actionable plans and estimation of costs. Planning typically produces time-bound roadmaps with estimations of human and financial resources. Plans not only focus on expanding or increasing the level of service or securing water of adequate quality for different purposes, but also on sustaining service levels while developing water resources sustainably, by ensuring continued investment in asset maintenance and adequate management regimes. Preparedness refers to the arrangements, capacities and knowledge developed by governments, response organisations, external agencies, communities and individuals to anticipate and plan, to be able to mitigate and respond effectively to the impact of potential or current shocks and stresses, including those related to climate change [42,43]. At a regional scale, planning and preparedness may also be broadened to encompass international agreements that govern the joint development and management of water infrastructure or management institutions such as River Basin Organisations (RBOs). This process can establish or maintain important channels of communication for countries that may have less than ideal diplomatic relationships, but which still need to work together on basic issues related to regional security such as disaster management within a shared basin.

Financing-This function relates to the ability to raise funds from different funding sources to cover all the elements of water services or water resources management throughout the entire 
lifecycle. This function also includes forecasting-i.e., the ability to project the costs under different scenarios—and budgeting-i.e., the ability to plan expenditure within a certain time horizon.

Management Arrangements-This function refers to the combination of organisational, managerial and institutional arrangements at national and sub-national levels, that support-or undermine - the functioning of the management entities. In service provision, it entails the definition of the service delivery model-who owns, who invests, who develops and who operates the infrastructure, who supervises and provides technical support, and the relationship among all these actors, and with the users. In water resources, management arrangements entail the processes for allocation and distribution of water resources (e.g., licensing and permitting), and the ownership and management of assets (dams, canals, etc.). At the transboundary scale, a management organisation such as an $\mathrm{RBO}$ can be an important platform for countries to formally work together on issues that promote or hinder water resources use, protection and/or development, in both upstream and downstream countries. In the context of disasters, emergencies and unforeseen situations, postdisaster management arrangements-including response and recovery-need to be in place. This relates to the provision of emergency services and providing necessary support during, or immediately after, a disaster event, to reduce damage and ensure safety, health and wellbeing of the affected people.

Monitoring, Evaluation and Learning-This function refers to ongoing, systematic processes of collecting, analysing, evaluating, and using data to track performance and inform planning and decision-making. Evaluation is an exercise to systematically and objectively assess progress and achievement of an outcome, which may include assessment of an activity, project, programme, strategy, policy, topic, theme, sector, operational area or institution's performance [44]. Evaluation helps in determining the relevance, impact, effectiveness, efficiency and sustainability of the intervention [44]. Learning includes formal and informal processes, whereby stakeholders exchange good practices and information and use the newly acquired knowledge in managerial decisions to adapt and improve policies and programmes.

Regulation-This function covers formal legal mechanisms, enforcement processes and other rules to ensure that stakeholders fulfil their mandates, and that standards, obligations and performance are maintained, as well as to ensure that the interests of each stakeholder are respected. The regulatory authorities set standards and establish rights, accompanied with ensuring effective accountability mechanisms to determine clear roles and responsibilities, monitoring mechanisms and penalties across sectors. Accountability mechanisms include organisational responsibilities for the core regulatory processes, and the links between regulators and those they regulate. Regulation also includes the capacity to enforce agreed standards and impose sanctions for noncompliance. Regulation tends to be the major sticking point between countries who must share a water resource. Countries often take a state-centric view on their water resources, which may be in direct competition with other countries who also share the same resource. Even in cases where a regulatory framework exists, there is a constant need to review and revise regulations to ensure that the needed flexibility to adapt to unforeseen challenges-e.g., climate threats-is present.

Capacity Development-This function refers to the processes by which organisations, society and individuals systematically stimulate, develop, strengthen and maintain their capabilities over time to set and develop their goals and objectives to be able to manage water services and resources sustainably $[43,45]$. This could be through knowledge development, awareness building, training and skills development, and improving systems and processes.

\subsection{Application of Governance Functions to Water Areas}

The content and activities included in each function will differ depending on the area of water that is addressed: water and sanitation services delivery, water resources management or transboundary waters. Table 3 seeks to visualise commonalities and differences among the functions, for these three water areas. 
Table 3. Elements of core water governance functions for different water areas.

\begin{tabular}{|c|c|c|c|}
\hline Function & Water and Sanitation & Water Resources & Transboundary Waters \\
\hline $\begin{array}{l}\text { Policy and } \\
\text { Strategy }\end{array}$ & $\begin{array}{l}\text { Water and sanitation services } \\
\text { related policies, legislations } \\
\text { and strategies. } \\
\text { Recognition of the human } \\
\text { rights to water and sanitation. }\end{array}$ & $\begin{array}{l}\text { Water resources-related policies, } \\
\text { legislations and strategies } \\
\text { (including ownership rights over } \\
\text { surface water and groundwater). } \\
\text { Key sectoral and regional } \\
\text { strategies beyond the water } \\
\text { sector affecting the use of water } \\
\text { resources, such as agriculture, } \\
\text { forestry, energy, or land use } \\
\text { plans. }\end{array}$ & $\begin{array}{l}\text { Regional water policies; foreign } \\
\text { policy; policies governing } \\
\text { regional economic integration. } \\
\text { Basin or sub-basin oriented } \\
\text { treaties and strategies. } \\
\text { RBO policies. } \\
\text { Fulfilment of water } \\
\text { resource-relevant obligations in } \\
\text { conventions and Multilateral } \\
\text { Environmental Agreements of } \\
\text { which a country is a party. }\end{array}$ \\
\hline Coordination & $\begin{array}{l}\text { Effective coordination among } \\
\text { all actors involved in service } \\
\text { delivery-national and local } \\
\text { government, donors, service } \\
\text { providers, users and other } \\
\text { stakeholders. }\end{array}$ & $\begin{array}{l}\text { Coordination among sectors and } \\
\text { actors at different levels (local, } \\
\text { landscape, river basin, national) } \\
\text { relying on water resources for } \\
\text { different uses (agriculture, } \\
\text { energy, industry, domestic etc..) } \\
\text { and interests (economy, } \\
\text { environment, social, etc.), across } \\
\text { the whole basin. }\end{array}$ & $\begin{array}{l}\text { Technical coordination: sharing } \\
\text { hydro/meteorology data; } \\
\text { operation of infrastructure that } \\
\text { impacts downstream flow; joint } \\
\text { conservation efforts. } \\
\text { High-Level political } \\
\text { coordination. } \\
\text { Coordination of technical and } \\
\text { political tracks. } \\
\text { Joint management bodies such } \\
\text { as RBOs. }\end{array}$ \\
\hline $\begin{array}{l}\text { Planning and } \\
\text { Preparedness }\end{array}$ & $\begin{array}{l}\text { Developing water and } \\
\text { sanitation infrastructure, } \\
\text { increasing the level of service } \\
\text { and sustaining it over time. } \\
\text { Increasing preparedness and } \\
\text { contingency planning for more } \\
\text { resilient services. } \\
\text { Strategic and annual planning. } \\
\text { Hazard and vulnerability } \\
\text { assessments for services. }\end{array}$ & $\begin{array}{l}\text { Strategic and action planning to } \\
\text { e.g., accommodate development } \\
\text { needs through water } \\
\text { infrastructure development or } \\
\text { nature-based solutions, to } \\
\text { protect and rehabilitate water } \\
\text { sources, waterways, } \\
\text { water-related ecosystems and } \\
\text { water resource infrastructure, } \\
\text { etc. } \\
\text { Hazard and vulnerability } \\
\text { assessments. } \\
\text { Basin/sub-basin disaster } \\
\text { preparedness plans. } \\
\text { Early Warning Systems. }\end{array}$ & $\begin{array}{l}\text { Regional level planning, often } \\
\text { including other sectors } \\
\text { (e.g., transportation, energy, } \\
\text { tourism) and often tied to } \\
\text { broader regional economic } \\
\text { integration. } \\
\text { Opportunities to identify or } \\
\text { mitigate drivers of conflict } \\
\text { and/or migration across borders. } \\
\text { Development of Master Plans } \\
\text { and multisector infrastructure } \\
\text { development opportunities. } \\
\text { Feasibility studies and joint } \\
\text { benefits assessments. }\end{array}$ \\
\hline Financing & $\begin{array}{l}\text { Sustainable financing of the } \\
\text { entire lifecycle of water and } \\
\text { sanitation services. } \\
\text { Operating and maintenance } \\
\text { costs; institutional support } \\
\text { costs; rehabilitation and } \\
\text { expansion costs. } \\
\text { Tariff setting and revenue } \\
\text { collection; water-related taxes; } \\
\text { willingness to pay; pro-poor } \\
\text { financing strategies; subsidies. } \\
\text { Reduction of non-revenue } \\
\text { water. } \\
\text { Private sector engagement in } \\
\text { financing of services. }\end{array}$ & $\begin{array}{l}\text { Water resource infrastructure } \\
\text { investment and cost-recovery. } \\
\text { Financing (including the } \\
\text { allocation of public funds) for } \\
\text { rehabilitation and protection of } \\
\text { water sources, waterways, } \\
\text { water-related ecosystems and } \\
\text { water infrastructure; and for } \\
\text { institutional support (e.g., river } \\
\text { basin authorities, stakeholder } \\
\text { participation). } \\
\text { Innovative financing } \\
\text { mechanisms to support } \\
\text { investment and cost recovery } \\
\text { (e.g., payment for ecosystem } \\
\text { services). } \\
\text { Financial buffers / insurance } \\
\text { schemes to support disaster } \\
\text { recovery. }\end{array}$ & $\begin{array}{l}\text { Joint financing of transboundary } \\
\text { water infrastructure or } \\
\text { management institutions. } \\
\text { Distribution of financial risk. } \\
\text { Development of regionally } \\
\text { shared resources (e.g., power } \\
\text { pools). }\end{array}$ \\
\hline
\end{tabular}


Table 3. Cont.

\begin{tabular}{|c|c|}
\hline Function & Water and Sanitation \\
\hline $\begin{array}{l}\text { Management } \\
\text { arrangements }\end{array}$ & $\begin{array}{l}\text { Asset ownership and } \\
\text { management of infrastructure; } \\
\text { service provision modalities } \\
\text { (e.g., public utility, local } \\
\text { government, private operator, } \\
\text { community-based model, } \\
\text { self-supply, etc.). } \\
\text { Infrastructure development } \\
\text { arrangements, including } \\
\text { expansion and rehabilitation } \\
\text { Operation and maintenance } \\
\text { arrangements. } \\
\text { Strategies, arrangements and } \\
\text { guidelines for water treatment } \\
\text { and re-use. } \\
\text { Mechanisms in place for the } \\
\text { provision of alternative water } \\
\text { supply (e.g., water trucking) } \\
\text { and contingency planning in } \\
\text { case of failing systems due to } \\
\text { extreme events. }\end{array}$ \\
\hline
\end{tabular}

Monitoring,

Evaluation and

Learning

\section{Systematic, routine}

monitoring of services and service delivery, including equity in access, service levels (in terms of quantity, quality, reliability), and functionality. Resource centres;

knowledge-sharing and peer learning mechanisms.

\begin{tabular}{|c|c|}
\hline $\begin{array}{l}\text { Allocation and distribution of } \\
\text { water resources (e.g., licensing } \\
\text { and permitting for water } \\
\text { affecting/using activities, etc.). } \\
\text { Asset ownership and } \\
\text { management (irrigation canals, } \\
\text { dams, hydropower plants etc.). } \\
\text { Key sectoral management that } \\
\text { affects water resource use and } \\
\text { quality (e.g., land, forestry, } \\
\text { agriculture). } \\
\text { Mechanisms in place for } \\
\text { responding and recovering from } \\
\text { extreme events and the use of } \\
\text { infrastructure (e.g., dam } \\
\text { opening) in case of emergency. } \\
\text { Local coping strategies to } \\
\text { address extreme events. }\end{array}$ & $\begin{array}{l}\text { Organisational and institutional } \\
\text { arrangements for shared waters } \\
\text { (Transboundary River } \\
\text { Commission, Transboundary } \\
\text { River Basin Authority, etc.). } \\
\text { Joint infrastructure } \\
\text { development, operation and } \\
\text { management and maintenance } \\
\text { (hydropower developments, } \\
\text { flood protection; cascading dam } \\
\text { management). } \\
\text { Mechanisms in place for } \\
\text { coordination of use of } \\
\text { infrastructure in case of } \\
\text { emergency. } \\
\text { Regional economic commissions } \\
\text { or environmentally focused } \\
\text { regional institutions. }\end{array}$ \\
\hline
\end{tabular}
Systematic monitoring of water Monitoring of transboundary quality and flow regimes, water technical cooperation. availability, water withdrawals, Monitoring of water related and consumption.
Participatory monitoring of water resources (e.g., citizen science).
Monitoring of progress in development and implementation of basin conflict.
Early and accident emergency warning systems. Systematic monitoring in shared waters.
Monitoring of compliance to transboundary agreements. management action plans.

Early Warning Systems.

\begin{tabular}{|c|c|}
\hline Regulation & $\begin{array}{l}\text { Regulation of both the service } \\
\text { provider and the service itself, } \\
\text { including explanations of } \\
\text { competency, economic } \\
\text { regulation and tariff, service } \\
\text { quality, consumer protection, } \\
\text { public health and environment. } \\
\text { Mechanisms for enforcement } \\
\text { at different levels. }\end{array}$ \\
\hline
\end{tabular}

Economic and environmental regulation such as: tariff setting for bulk water, setting water abstraction limits, water discharge and ambient water quality standards and control. Defining policing procedures. Mechanisms for enforcement at different levels, including monitoring of water discharges. Mechanisms to incentivise sustainable/efficient use of water resources (e.g., certification).

International water laws and conventions-norms, declaration, protocols, commitments and rules governing the relations and arrangement between the shared waters.

Regulation happens at two levels: (i) through transboundary joint agreements; and (ii) by integrating transboundary rules and national rules, for example Environmental Impact Assessments (EIAs).

\begin{tabular}{ll}
\hline Capacity & Capacity development \\
Development & strategies and centres for \\
& continuous training for \\
& ministries staff, service \\
providers, regulators, CSOs & and users; Capacity \\
development for both \\
individuals and organisations. \\
In decentralised contexts, it \\
might require continuous \\
technical support for the local \\
actors who have assumed new \\
institutional roles.
\end{tabular}

Availability of capacity development strategies and centres for continuous training within Ministries, Basin organisations, Agencies and local level organisations. Continuous learning and adaptive management. Broadening access to decision making processes to neglected or vulnerable groups.
Developing consensual knowledge around shared water resource availability and quality. Developing capacities for relevant actors (RBO, Regional Economic Commissions, CSO, Media, etc.) Strengthening regional or geopolitical security through water diplomacy. 
In addition, the maturity level and the degree of implementation of each core governance function will vary depending on the context. In particular, when a sector is being established, not all functions might be fully in place. There can also be aspects that need to be addressed first, or that are dependent on others. For example, sector policy and strategy would logically precede planning and coordination; and management and service delivery arrangements could then follow. However, there are multiple cases where policy and legal frameworks stay under discussion for a long time, while water resources management and service delivery still need to take place on a daily basis (Appendix A8). In the transboundary setting, water issues are often viewed through a national security lens and end up embedded or entangled within a broader set of socioeconomic or geopolitical issues that can appear (and sometimes are) completely unrelated to the water sector. The legitimate but often competing interests of multiple countries with a stake in a shared water resource require governments to work together, and these political processes can take decades. Developing a common knowledge of a shared resource and an understanding of the needs and ambitions of neighbouring countries with regard to development and management can simultaneously be the foundation for achieving the practical benefits commonly linked to development, as well as the foundation for a productive, peaceful, and cooperative relationship from a geopolitical perspective. Another example is that regulation should precede the establishment of service models, to be able to set standards on e.g., the quality of service, or tariffs. On many occasions, regulation comes only as a result of observed disparities in performance, service standards and prices across different service providers (Appendix A9). Similarly, establishing rigid water allocation regimes without sufficient monitoring capacities to evaluate changes in water resources over time (especially important in face of climate change) can lead to unsustainable use of water resources. It is therefore important to consider that there is not a pre-established sequence of functions for all situations, and that they interrelate with each other. Hence, to different extents, all functions take place in a more formal or informal manner in a given context, and it is important to understand how they play out, in order to ensure availability and sustainable management of water resources and services.

\subsection{The Governance Attributes}

Water governance attributes describe how the governance functions are performed. Several initiatives have worked on defining desirable attributes for governance. For instance, the UN "good" governance principles identify some of the governance qualities that establish a baseline for good governance. They include promoting legitimacy and voice through participation, consensus, and informed decisions; the performance of institutions and processes through responsiveness, effectiveness, and efficiency; promoting accountability and transparency; ensuring fairness by implementing equity, rule of law, and conflict management [31]. These principles are reiterated through the Human Rights Based Approach (HRBA) to water governance, derived from the 1948 Universal Declaration of Human Rights which includes the principles of universality and inalienability; indivisibility; interdependence and inter-relatedness; equality and non-discrimination; participation and inclusion; and accountability and rule of law [46]. These principles are part of the content of all human rights, including the human rights to water and sanitation $[47,48]$. The OECD water governance principles, which are rooted in the UN good governance principles and promote: legitimacy; transparency; accountability; human rights; rule of law and inclusiveness in water governance processes, emphasise that water governance systems should be designed based on the challenges that they need to address to build a sustainable water sector. It considers that governance is good if it can help address and solve the key water challenges, through a combination of both bottom-up and top-down approaches, respond to place-based needs and foster constructive and effective state-society relations [49]. In some water governance literature, these attributes have been discussed when striving to attain certain outcomes, such as sustainability and resilience [15,50-52]. In the resilience discourse, governance attributes such as polycentric and multilayered, coordination and collaboration, participation, deliberation, equity and inclusiveness, accountability and transparency, and adaptive 
capacity have been identified as the contributing factors for enhancing resilience [17,53-57]. A focus on these attributes promotes improving institutional arrangements (decision-making process, institutional flexibility), social capital (trust, network and leadership) and individual capacity (drawing from experiences towards innovative solutions, self-organising, knowledge generation, learning), which further helps in building resilience [35].

In this section, we list and define the key governance attributes. The aim is to provide a list of the possible attributes for the different functions. Some related attributes have been grouped. For example, the good governance principles attribute "equity and inclusiveness" is incorporated into the definition of the attribute "inclusiveness". The attributes are related to how governance functions could be performed, e.g., having a participatory process for the governance function on planning. By way of example, in the context of planning to protect water sources there are different elements such as preventing discharge of waste, pollutants or untreated water from domestic, industrial or agricultural use; and optimised water use and practices in agriculture in order to stop nutrients from entering aquatic systems. In order to achieve and be able to sustain those protection plans, the participation of a broad spectrum of stakeholders in the planning process is needed. This includes active and meaningful participation of both planners and other stakeholders, including the vulnerable or marginalised groups having the opportunity to influence the decisions [58].

Attributes are also linked to each other. In order to achieve certain outcomes, some need to complement each other. For a multilevel governance structure to be effective it must be coherent and complimented by other governance attributes, such as effective and informed participation among the multiple decision-making centres and actors, for which transparent decision-making and access to information is needed. This would further require an accountability mechanism to be in place that is effectively implemented, which will ensure clearly defined roles and responsibilities, and compliance for actions taken at different levels and layers.

The definitions of the attributes follow:

Multilevel governance implies that there are decision-making centres or governing authorities at different levels (vertical) or layers (horizontal i.e., arrangements that may not necessarily stand in hierarchical order but have a certain level of independence and interdependence between institutions within the same level of governance) [55,59]. Such governance systems can be of different forms, and the terminologies are sometimes used interchangeably. Within this, nested and polycentric governance are common descriptors used in academic literature. Nested systems are those where key governance functions are organised into multiple reinforcing layers of governance but are not necessarily independent of each other [60], i.e., with functional linkages between levels or layers. Polycentric systems are those where decision centres are present in different layers and are independent of each other, with a certain degree of power and financial autonomy (which may not be the case in a hierarchical structure), such as in municipalities [55,57]. This attribute is closely linked to decentralisation and its different modalities (Appendix A10). For example, at a city level, if the power and control related to water management is distributed among multiple administrative units, or different municipal authorities within a metropolitan area, then that is a polycentric system.

Participation implies the meaningful and active involvement of a broad spectrum of stakeholders, including vulnerable or marginalised groups in decision making processes. The human rights framework to water and sanitation defines six procedural elements as crucial for achieving free, active, and meaningful participation: involving people in design of the participatory procedures; creating access to participatory spaces; enabling environment of free and safe participation; access to reliable and complete information in timely manner, which is easy to understand and comes at no cost; providing support to enable effective contributions from the stakeholders; and having the opportunities to influence decisions taken in the sector along with the right to know how their inputs were considered, what decisions were made and implemented, and on what grounds [61]. However, these procedural aspects also need to be adapted to the context, and the level of capacity and resources, and the attitudes towards the participatory process are also essential for its success [41]. At transboundary scale, two or 
more countries are involved, and the sphere of participation is often broadened, in recognition of the geopolitical implications of water management.

Deliberation features mechanisms that facilitate open communication and discussion through mediums of debate, dissent, mediation and negotiation to create a common ground of collective action. For instance, the role of deliberation, mediation, negotiation and dispute resolution mechanisms are key instruments in water conflict management and in improving transboundary water cooperation processes, by building trust between riparian states of shared waters. Often this is driven by the political will and commitment, which define the potential of optimal, or at least cooperative, outcomes. Regardless of the state of conflict or cooperation between countries, a deliberative process is required to establish a joint vision and consensual understanding of a shared resource (quantity and quality). This governance attribute could also be important in the context of conflict management and cooperation between private and public sectors and utilities involved in water services provision; or on issues arising between communities and decision makers. The role of third-party external entities becomes crucial in such processes.

Inclusiveness is recognising the rights of individuals and groups across different categories, needs and vulnerabilities, and without any kind of discrimination based on race, colour, age, gender, religious affiliation, ethnicity, language, disability, economic backgrounds or any other conditions of origin. It also concerns taking into consideration these diverse social, economic, and cultural aspects, along with taking special account of the vulnerable groups, minorities and indigenous people when performing different governance functions, contributing to balancing differences in power. This attribute is closely related to equity, for example by designing and implementing pro-poor financing strategies, equitable distribution of water; or mainstreaming gender in planning, policy, financing, monitoring of water services and resources.

Accountability refers to the principle whereby elected officials and those that have a responsibility in water services or water resources management account for their actions and answer to those they serve [62,63]. The Human Rights framework identifies three essential principles for building accountability (a) responsibility: defining roles and responsibilities in service delivery and enabling coordination between different stakeholders, (b) answerability: by providing reasoned justifications and explanation for their actions and decisions to those they affect, (c) enforceability: by providing monitoring, supporting and enforcing compliance for the use of corrective and remedial action where necessary, such as sanctions for corrupt behaviour [62]. However, accountability in the transboundary setting is often skewed towards national interests, as elected officials might tend to promote the interests of their constituents above all else.

Transparency refers to "openness and public access to information so that citizens can understand the decision-making processes that affect them, and are knowledgeable about the standards to expect from public officials" [64]. Transparency requires governments, companies, organisations and individuals to facilitate all means for citizens to understand the decisions that may affect them; and it requires the information to be usable through open data, that is accurate, available, complete, conformant, consistent, credible, processable, relevant and timely [65]. Transparency is vital to the underlying trust in a transboundary relationship, where access to data can be strategically withheld or manipulated to strengthen the negotiating positions of one or more countries.

Evidence-based decision-making around water seeks to identify and leverage reliable technical and scientific, empirical and contextual evidence for decision-making. This includes collection and dissemination of accurate and current knowledge and information related to natural and social sciences; drawing upon inputs from specialists and subject matter experts and using advanced information systems; learning from past failures and successes; and including local knowledge and cultural values. It is important to ensure that the information reaches the appropriate decision makers and technical staff involved in water-related decision-making in a timely manner $[52,66,67]$.

Efficiency in process management means that processes and institutions produce results that meet the needs of society while making the best use of resources at their disposal [31]. This includes 
workflows, specific activities, and steps that must be taken with the objective of providing a clear idea of how the processes serve to transform the inputs to an effective and sustainable output.

Impartiality and Rule of law refers to having legal frameworks and mechanisms that are designed and enforced impartially, in a fair and non-discriminatory manner, reflective of the human rights-based approach. The UN [68] refers to 'Rule of law' as a core principle of governance, where all (including institutions, entities, public, private, the state) are accountable to laws established that are consistent with international human rights norms and standards. In addition, it is required to ensure adherence to the principles of supremacy of law; equality before the law; accountability to the law; fairness in the application of the law; separation of powers; participation in decision-making; legal certainty; avoidance of arbitrariness, and procedural and legal transparency. While there are two international conventions that establish a legal framework for protection, management, and development of transboundary waters $[69,70]$, many countries view them as an afront to their sovereignty and simply refuse to become party to, or observe them. There is no mechanism to enforce either treaty, or to oblige countries who have not voluntarily ratified them, to do so.

Adaptiveness, described as one of the attributes under adaptive governance in relation to resilience means the ability to self-organise, learn, respond, cope and use adaptive management strategies in situations of uncertainties, risk and nonlinearities. Self-organising is a common feature of adaptiveness and it refers to the ability of a system to maintain and re-create its identity by safeguarding itself from the impacts of other systems [55,71]. It is important to ensure that during situations of uncertainties and risks, the system is capable of self-organising through formal and informal arrangements and that there are mechanisms and platforms to facilitate collective learning, knowledge sharing and innovative approaches for the implementation of the existing governance functions; for example, establishing capacity development mechanisms that promote awareness raising campaigns, support community or stakeholder networks and mobilisation.

\subsection{The Governance Outcomes}

The performance of core governance functions can only be understood when linked to how these functions are conducted (attributes), leading to the desired outcomes of the governance process. Outcomes are by nature interlinked and interdependent. We adapt herein the Orders of Outcomes framework proposed by Olsen et al. [36] and Olsen [37] for the governance of source-to-sea systems. They propose measurable outcomes disaggregated into four 'orders' that while not accumulating in a strictly sequential manner, lead to the ultimate long term goal of sustainable forms of development [72], as shown in Table 4.

Table 4. Four "orders" of outcomes in a governance program (adapted from [72]).

\begin{tabular}{ll}
\hline Order of Outcomes & \multicolumn{1}{c}{ Description } \\
\hline First & Creation of the enabling conditions for a governance initiative. \\
Second & Behaviour change of resource users and key institutions. \\
Third & Achievement of desired changes in societal and environmental conditions. \\
Fourth & A resilient social-ecological system where desired conditions are sustained. \\
\hline
\end{tabular}

The First Order of outcomes relates to the setting in place of the enabling conditions necessary to perform all governance functions, including agreement on goals and objectives in combination with the necessary commitment, buy-in and capacity among key government agencies and stakeholders. They are context-based, thus changing from programme to programme and from region to region. At the transboundary scale, the first order is often underpinned by geopolitics and the state of conflict or cooperation between countries. Hence, finding common ground and establishing a joint vision for the water system and its governance at a basin or regional scale is an important First Order outcome in these settings. 
The Second Order of outcomes come during implementation and refer to the change in behaviour among user groups and institutions in performing the governance functions. They include (1) changes in how institutions and groups relate to one another (e.g., enhanced cooperation, improved trust); (2) changes in how user groups relate to the resource (e.g., responsible water consumption, compliance with agreed regulations for water discharge); (3) evidence of implementation of the agreed vision, goals and objectives (e.g., financing is made available to support implementation, and monitoring and evaluation takes place) [37].

The Third Order of outcomes are defined by the goals and objectives set as part of the first order outcomes. While Third Order outcomes are context-based, outlined as part of a policy and strategy process, they generally aim for internationally agreed outcomes (e.g., Sustainable Development Goals), such as improved status of the water resource and its related ecosystems, increased and equitable access to services and strengthened resilience.

The Fourth Order of outcomes are achieved when the desired social and ecological conditions remain over time, and the system is able to adapt and absorb changes and stresses and "development meets the needs of the present without compromising the ability of future generations to meet their own needs" [73].

\subsection{An Operational Framework for Water Governance}

The combination of functions and attributes to achieve certain outcomes is influenced by the existing values and aspirations of stakeholders taking part in governance processes, as well as by the amount of available resources that are allocated for this purpose. To start with, agreed values tend to be formulated as "principles" in policy and strategy documents. Aspects of international ideals such as the willingness to attain the Sustainable Development Goals, the recognition of the human rights to water and sanitation, the "benefit sharing" in transboundary waters, or the "polluter and user pays principles" in water resources are examples of these type of principles, which aim to transcend across water governance. In addition, it is important to consider customary practices, such as existing (recognised or not) local governance systems of water commons (e.g., traditional management of irrigation schemes, indigenous ecological governance models). The recognition and integration of these practices can be essential for achieving the intended outcomes of governance. Cultural beliefs and social norms related to water, and particularly sanitation and hygiene, are essential elements to be considered.

The actual quality and extent of implementation of functions also depends on the individual values and the aspirations of both key decision makers and citizens. Integrity refers to individuals and organisations that embrace a moral and ethical value of professionalism, honesty, equity, transparency and openness in their governance functioning, which creates a barrier to corruption [74,75]. Hence, the meaning of aspects such as political leadership, or the ethics of public services also constitute essential elements to understand governance in a given context. For individuals, their role as global citizens (i.e., the power of their individual decisions) or as part of global social change organisations also influences governance processes. During the drought crisis in Cape Town in 2017-2018, by way of example, the biggest water saving was due to the controlled reduction of demand, reducing the individual consumption of water, mainly through a combination of awareness raising and tariff increases.

In summary, the values and aspirations, and resulting behaviours of individuals and organisations, linked to social norms, are additional components of the governance puzzle, which cut across the whole process, as depicted in Figure 1. Even if our operational definition directs towards outcomes, the reality shows that different stakeholders might have different entry points for governance work. An instrumental entry point would contend that the focus should be on first developing the functions, and then select which attributes should be in place to achieve specific outcomes. A visionary approach would start by defining the desired outcomes. From there, it would be necessary to identify the adequate combination of functions and attributes to achieve such outcomes. Another entry point is to 
focus on specific attributes. Then, the way functions are carried out would be modified to incorporate the attributes. A focus on improving accountability, by way of example, would highlight the need to develop an adequate policy framework that sets clear roles, improving regulation and access to information, and monitoring of results, with clear regulatory procedures.

Changing values can also be a valid entry point to work with governance. Intercultural approaches, awareness and/or behaviour change campaigns have been the focus of several initiatives (see e.g., [76,77]). At the institutional level, supporting political leadership [78], the ethics of public services [79], or the role of global citizens [80] have been adopted as key strategies by different programs.

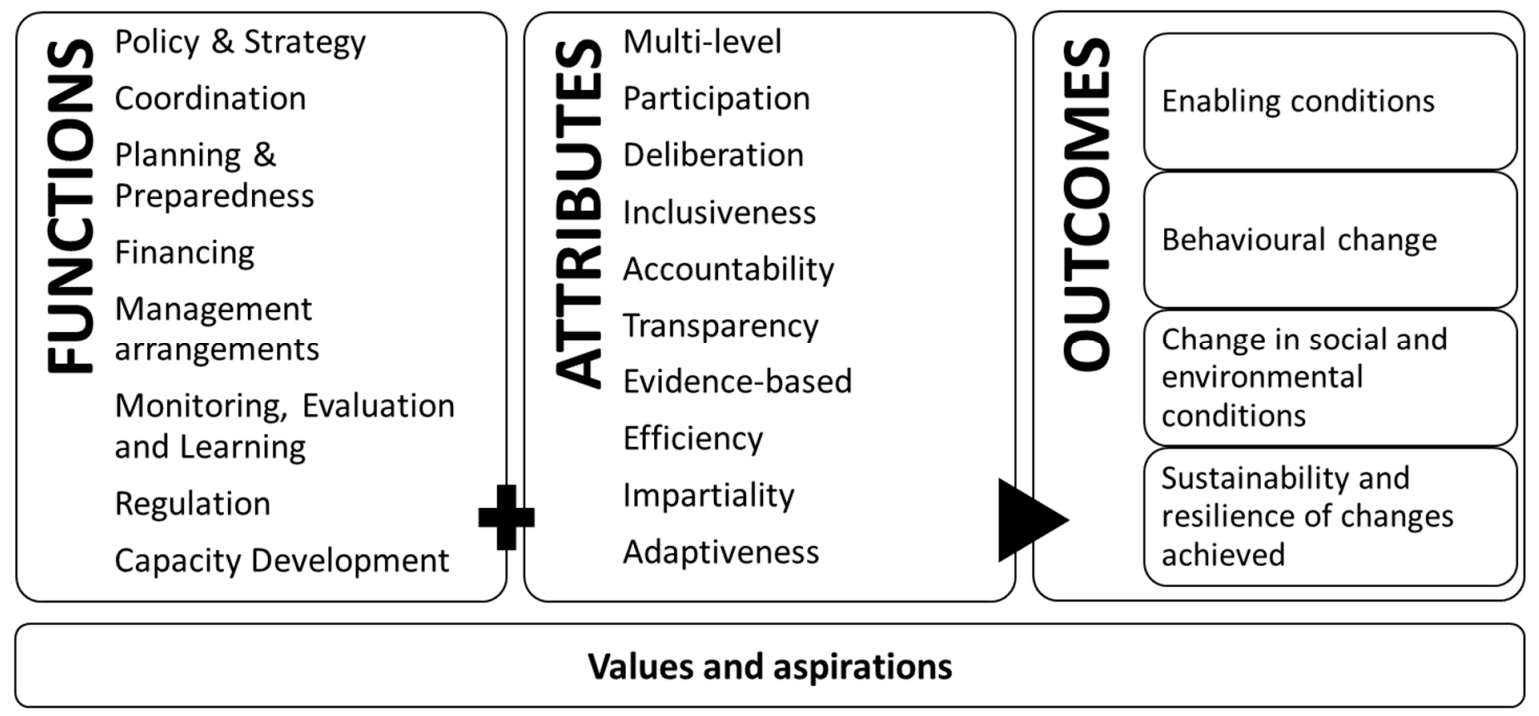

Figure 1. The Governance Framework, as a combination of functions, attributes and outcomes.

\subsection{Applying the Water Governance Framework}

The previous sections describe the integration of governance functions, attributes and outcomes within one integrated operational framework. This section seeks to illustrate the practical utility of the proposed approach by showing how this framework is implemented in one diagnostic and planning tool: the WASH Bottleneck Analysis Tool (WASH BAT), which seeks to identify WASH governance areas in need of further support, and articulate costed and prioritised action plans. The tool bases the diagnosis of WASH services on the governance functions and the attributes; this section thus sheds light on the strengths, weaknesses and usefulness of the proposed conceptualisation of water governance.

The long term goal of using the WASH BAT (third order of outcome) is to achieve more sustainable, equitable and resilient WASH services. The tool enables a systematic identification of factors (or 'bottlenecks') that hamper or limit sustainable service delivery, and, by facilitating dialogue between stakeholders, helps to define activities aimed at removing the root causes of these bottlenecks. This is achieved by assessing the enabling environment for WASH service delivery. The assessment is mainly structured around the governance functions presented herein [33], which have been regrouped into five 'building blocks' [34]. The performance of key functions in each building block are scored through a set of criteria, and barriers and bottlenecks to delivering specific outcomes of first and second order are identified. Both the outcomes and the criteria incorporate a number of governance attributes. For instance, the first criterion of the "Sector Policy and Strategy" building block refers to the need to undertake "evidence-based" policy (e.g., coverage data, service quality, available financing, population impacts of poor services), thus making an explicit link to this attribute. The related first order of outcome for the urban drinking water sector reads "Urban water policy for households and institutions backed by a legal framework is approved by cabinet and used by stakeholders, containing national service norms and addressing social norms, equity aspects, rules for resource allocation and priority 
setting, and future adaptation requirements". It refers to the attributes of inclusiveness, accountability and transparency.

In the end, the WASH BAT allows, on one hand, a structured diagnosis of the sector, where identified bottlenecks can be easily tracked back and related to the governance functions, attributes and outcomes. On the other hand, activities for the removal of bottlenecks are agreed, sequenced and prioritised, costs are estimated, and funds are allocated to the prioritised activities [81]. The output of the diagnosis, i.e., a coordinated plan of activities, therefore links costed and prioritised actions to one or more specific functions of the WASH sector and broader enabling environment, which can be monitored and fine-tuned over time until the bottlenecks are resolved and the expected outcomes are achieved.

\section{Conclusions}

There is some ambiguity in both the concept and the approach of governance, which hampers operationalisation by decision makers and practitioners alike. In practice, some organisations explicitly working on water governance share similar approaches, to a certain extent, and recognise specific governance functions in their frameworks. The focus of other institutions is on certain attributes, while specific programmes might have governance outcomes as the focus.

This paper presents an operational framework for unpacking water governance. The framework has the two-fold aim of providing a harmonised set of governance functions and attributes, and to illustrate how the functions and attributes interrelate to achieve specific outcomes. The governance functions seek to capture the key elements and processes that need to be in place to be able to develop and manage water resources and services (what). Closely linked to the functions are the attributes, which relate to how the functions are implemented. However, these are interrelated, all shaped by the values and aspirations of stakeholders (why). Hence, water governance is as a combination of functions, performed with certain attributes, to achieve one or more desired outcomes, all shaped by the values and aspirations of individuals and organisations. As such, water governance is considered as a means to an end rather than an end in itself.

This framework can contribute to improved understanding of water governance through its future use: (i) to understand how in practice (at national and local level) different functions are linked to certain attributes for achieving desired outcomes, basing the analysis on the proposed framework; (ii) to understand how countries self-assess their weaknesses in relation to the framework, and extract general common trends; (iii) to improve governance intervention design as a result of increased understanding of the water governance pathway. To illustrate, the usefulness of the proposed framework has been proven by showing how governance functions and attributes can be embedded in the WASH BAT, a tool that supports the development of structured multistakeholder diagnoses and related action plans to foster progress in the WASH sector.

The next steps for developing this framework will be to: (i) further detail operational activities (subfunctions) within and between the core functions, which will allow for more detail in the assessment of governance, as well as for adaptability to different contexts; (ii) to develop practical guidance for how to apply certain attributes when performing water governance functions; and (iii) to understand better how working with values and behaviours can improve governance outcomes.

Author Contributions: Conceptualisation, A.J., P.S., R.G., P.A., J.L., B.L.L., K.S.; literature review, P.S. and A.J.; analysis of results and discussion, A.J., P.S., R.G., P.A., J.L., B.L.L., K.S., R.W; writing-original draft, R.G., P.S., R.W. and A.J.; writing-review and editing, A.J., P.S., R.G., P.A., J.L., B.L.L., K.S., R.W. All authors have read and agreed to the published version of the manuscript.

Funding: Funding for the Stockholm International Water Institute authors was provided by the Swedish International Development Cooperation Agency.

Acknowledgments: The authors would like to extend sincere thanks to all participants in the different rounds of consultations. Special thanks go to David Hebart-Coleman, Elizabeth Yaari, Virginia Mariezcurrena, Anna Tengberg, and Maria Vink for their further review and inputs into the draft. The authors would also like to thank the reviewers for all their comments. 
Conflicts of Interest: The authors declare no conflicts of interest.

\section{Appendix A}

(1) Sustainable development first appeared in 1987 United Nations report Our Common future. (2) The United Nations Office for Disaster Risk Reduction (2009) defines resilience as "the ability of a system, community or society exposed to hazards to resist, absorb, accommodate to and recover from the effects of a hazard in a timely and efficient manner, including through the preservation and restoration of its essential basic structures and functions". (3) Resilience theorists treats social-ecological systems as an integrated complex adaptive system in which social (human) and ecological (biophysical) subsystems, each with multiple levels, are intertwined and interdependent $[54,71,82,83]$. Scholar Elinor Ostrom introduced a framework for analyzing sustainability of Social-Ecological Systems [84]. (4) This paper refers to transboundary in the context of shared waters -the aquifers, and lakes and river basins shared by two or more countries. (5) The initial list of functions and attributes was presented at the WASH Bottleneck Analysis Tool workshop expert meeting in Washington DC, organised by UNICEF, in January 2016. (6) See https://www.wsp.org/about/Water-and-Sanitation-Organizations, 1st March 2019. (7) See https://www.raptim.org/55-water-ngos-know/, 1 March 2019. (8) By way of example, in El Salvador, water law has been in debate for more than a decade, with multiple proposals that never got approved. (9) See, for instance, current effort of the Government of Ethiopia to assess options for regulation of the water services. (10) For a description of different definitions and modes of decentralisation see: http://www.cifor.org/publications/pdf_files/interlaken/Compilation.pdf

\section{References}

1. United Nations World Water Assessment Programme (WWAP). Water for people, water for life: The United Nations World Water Development Report; United Nations Educational, Scientific and Cultural Organization (UNESCO): Paris, France, 2003.

2. Rogers, P. Water governance, water security and water sustainability. In Water Crisis: Myth or Reality Marcelino Botin Water Forum 2004; Rogers, P.P., Llamas, M.R., Cortina, L.M., Eds.; Taylor and Francis: London, UK, 2006; pp. 3-35, ISBN 978-0-415-36438-6.

3. United Nations Development Programme (UNDP). Human Development Report 2006. Beyond scarcity: Power, Poverty and the Global Water Crisis; United Nations Development Programme: New York, NY, USA, 2006.

4. Arnold, C.A.; Gosnell, H.; Benson, M.H.; Craig, R.K. Cross-interdisciplinary insights into adaptive governance and resilience. Ecol. Soc. 2017, 22. [CrossRef]

5. Hugé, J.; Waas, T.; Dahdouh-Guebas, F.; Koedam, N.; Block, T. A discourse-analytical perspective on sustainability assessment: Interpreting sustainable development in practice. Sustain. Sci. 2013, 8, 187-198. [CrossRef]

6. Together 2030 Sustainable, Resilient and Inclusive Societies - The Path Towards Transformation. Together 2030 Global Advocacy Working Group, 2018. Available online: https://sustainabledevelopment.un.org/ content/documents/18829Together2030_Sectoral_Paper_HLPF2018.pdf (accessed on 1 September 2019).

7. Global Commission on Adaptation. Adapt Now: A Global Call for Leadership on Climate Resilience; Global Commission on Adaptation and Water Resource Institute: Rotterdam \& Groningen, The Netherlands, 2019.

8. Howard, G.; Bartram, J. Vision 2030: The Resilience of Water Supply and Sanitation in the Face of Climate Change; World Health Organization: Geneva, Switzerland, 2010.

9. Wang, C.-H.; Blackmore, J.; Wang, X.; Yum, K.-K.; Zhou, M.; Diaper, C.; McGregor, G.; Anticev, J. Overview of Resilience Concepts, with Application to Water Resource Systems; Water Cooperative Research Centre: Canberra, Australia, 2009.

10. Rogers, P.; Hall, A.W. Effective Water Governance; TEC Background Papers; Global Water Partnership: Stockholm, Sweden, 2003.

11. United Nations World Water Assessment Programme (WWAP). Water: A Shared Responsibility. The United Nations World Water Development Report 2; United Nations Educational, Scientific and Cultural Organization (UNESCO): Paris, France, 2006. 
12. Graham, J.; Amos, B.; Plumptre, T. Principles for Good Governance in the 21st Century; Institute on Governance (IOG): Ontario, Canada, 2003.

13. World Bank. Governance and Development (English); The World Bank: Washington, DC, USA, 1992.

14. Blühdorn, I.; Deflorian, M. The Collaborative Management of Sustained Unsustainability: On the Performance of Participatory Forms of Environmental Governance. Sustainability 2019, 11, 1189. [CrossRef]

15. Chaffin, B.C.; Gosnell, H.; Cosens, B.A. A decade of adaptive governance scholarship: Synthesis and future directions. Ecol. Soc. 2014, 19, 56. [CrossRef]

16. Cosens, B.; Gunderson, L.; Chaffin, B. The Adaptive Water Governance Project: Assessing Law, Resilience and Governance in Regional Socio-Ecological Water Systems Facing a Changing Climate. Ida. Law Rev. 2015, $51,27$.

17. Folke, C.; Hahn, T.; Olsson, P.; Norberg, J. Adaptive Governance of social-ecological systems. Annu. Rev. Environ. Resour. 2005, 30, 441-473. [CrossRef]

18. Pahl-Wostl, C. A conceptual framework for analysing adaptive capacity and multi-level learning processes in resource governance regimes. Glob. Environ. Chang. 2009, 19, 354-365. [CrossRef]

19. World Water Council. Ministerial Declaration of The Hague on Water Security in the 21st Century 2000; World Water Council: The Hague, The Netherlands, 2000.

20. Water Supply and Sanitation Collaborative Council (WSSCC). Ministerial Declaration of the Bonn International Conference on Freshwater 2001; Water Supply and Sanitation Collaborative Council (WSSCC): Bonn, Germany, 2001.

21. Akhmouch, A.; Correia, F.N. The 12 OECD principles on water governance - When science meets policy. Util. Policy 2016, 43, 14-20. [CrossRef]

22. Akmouch, A. Water Governance in Latin America and the Caribbean: A Multi-Level Approach. OECD Reg. Dev. Work. Pap. 2012.

23. OECD. Water Governance in OECD Countries; OECD Studies on Water; OECD Publishing: Paris, France, 2011; ISBN 9789264119277.

24. Ménard, C.; Jimenez, A.; Tropp, H. Addressing the policy-implementation gaps in water services: The key role of meso-institutions. Water Int. 2018, 43, 13-33. [CrossRef]

25. Kummu, M.; Guillaume, J.H.A.; de Moel, H.; Eisner, S.; Flörke, M.; Porkka, M.; Siebert, S.; Veldkamp, T.I.E.; Ward, P.J. The world's road to water scarcity: Shortage and stress in the 20th century and pathways towards sustainability. Sci. Rep. 2016, 6, 38495. [CrossRef] [PubMed]

26. Lautze, J.; de Silva, S.; Giordano, M.; Sanford, L. Putting the cart before the horse: Water governance and IWRM. Nat. Resour. Forum 2011, 35, 1-8. [CrossRef]

27. Allan, T. The Middle East Water Question: Hydropolitics and the Global Economy; I.B.Tauris \& Co. Ltd.: London, UK; New York, NY, USA, 2001; ISBN 9781860648137.

28. Rauschmayer, F.; van den Hove, S.; Koetz, T. Participation in EU Biodiversity Governance: How Far beyond Rhetoric? Environ. Plan. C Gov. Policy 2009, 27, 42-58. [CrossRef]

29. De Stefano, L.; Svendsen, M.; Giordano, M.; Steel, B.S.; Brown, B.; Wolf, A.T. Water governance benchmarking: Concepts and approach framework as applied to Middle East and North Africa countries. Water Policy 2014, 16, 1121-1139. [CrossRef]

30. Jacobson, M.; Meyer, F.; Tropp, H.; Oia, I.; Reddy, P. User's Guide on Assessing Water Governance; United Nations Development Programme: Stockholm, Sweden, 2013.

31. UNESCAP. What Is Good Governance? United Nations Economic and Social Commission for Asia and The Pacific: Bangkok, Thailand, 2009.

32. Jiménez, A.; Jawara, D.; LeDeunff, H.; Naylor, K.A.; Scharp, C. Sustainability in Practice: Experiences from Rural Water and Sanitation Services in West Africa. Sustainability 2017, 9, 403. [CrossRef]

33. United Nations. Children's Fund Strengthening Enabling Environment for Water, Sanitation and Hygiene (WASH): Guidance Note; United Nations Children's Fund: New York, NY, USA, 2016.

34. Sanitation and Water for All (SWA). Building Blocks. Available online: http://sanitationandwaterforall.org/ priority-areas/building-blocks/ (accessed on 1 July 2019).

35. ARUP. SIWI The City Water Resilience Approach; ARUP: London, UK, 2019.

36. Olsen, S.B.; Lowry, K.; Tobey, J. A Manual for Assessing Progress in Coastal Management; University of Rhode Island Coastal Resources Center: Narragansett, RI, USA, 1999. 
37. Olsen, S.B. Frameworks and indicators for assessing progress in integrated coastal management initiatives. Ocean Coast. Manag. 2003, 46,347-361. [CrossRef]

38. Olsen, S.; Page, G.; Ochoa, E. The Analysis of Governance Responses to Ecosystem Change A Handbook for Assembling a Baseline. LOICZ Reports Stud. 2009, 34, 1-87.

39. Michaud, W.R. Evaluating the outcomes of collaborative modeling for decision support. J. Am. Water Resour. Assoc. 2012, 49, 693-699. [CrossRef]

40. Hassenforder, E.; Smajgl, A.; Ward, J. Towards understanding participatory processes: Framework, application and results. J. Environ. Manage. 2015, 157, 84-95. [CrossRef]

41. Jiménez, A.; LeDeunff, H.; Giné, R.; Sjödin, J.; Cronk, R.; Murad, S.; Takane, M.; Bartram, J. The Enabling Environment for Participation in Water and Sanitation: A Conceptual Framework. Water 2019, 11, 308. [CrossRef]

42. United Nations. Disaster Preparedness for Effective Response: Guidance and Indicator Package for Implementing Priority Five of the Hyogo Framework; United Nations Secretariat of the International Strategy for Disaster Reduction (UN/ISDR) and the United Nations Office for Coordination of Humanitarian Affairs (UN/OCHA): Geneva, Switzerland, 2008.

43. UNISDR. 2009 UNISDR Terminology on Disaster Risk Reduction; International Stratergy for Disaster Reduction (ISDR): Geneva, Switzerland, 2009.

44. United Nations Development Programme (UNDP). Handbook on Planning, Monitoring and Evaluating for Development Results; United Nations Development Programme (UNDP): New York, NY, USA, 2009.

45. United Nations Development Programme (UNDP). Capacity Development: A UNDP Primer; Wignaraja, K., Ed.; United Nations Development Programme (UNDP): New York, NY, USA, 2009.

46. Grönwall, J.; Schmitz, T.; Arrieta, L. Human-Rights Based Approach to Integrated Water Resources Management: Training Manual and Facilitator's Guide; Cap-Net, UNDP-SIWI Water Governance Facility, WaterLex and REDICA: Pretoria, South Africa, 2017.

47. United Nations General Assembly. The Human Right to Water and Sanitation; Resolution A/RES/64/292 2010; United Nations General Assembly: New York, NY, USA, 2010; p. 3.

48. United Nations General Assembly. The Human Rights to Safe Drinking Water and Sanitation; Resolution A/RES/70/169; United Nations General Assembly: New York, NY, USA, 2015; p. 6.

49. OECD. OECD Principles on Water Governance Welcomed by Ministers at the OECD Ministerial Council Meeting on 4 June 2015; Directorate for Public Governance and Territorial Development, Organization for Economic Cooperation and Development: Paris, France, 2015.

50. Akamani, K. Adaptive Water Governance: Integrating the Human Dimensions into Water Resource Governance. J. Contemp. Water Res. Educ. 2016, 158, 2-18. [CrossRef]

51. Harrison, N. Good Governance: Complexity, Institutions, and Resilience; Sustainable Development Institute and University of Wyoming: Montreal, QC, Canada, 2003.

52. Pahl-Wostl, C. An Evolutionary Perspective on Water Governance: From Understanding to Transformation. Water Resour. Manag. 2017, 31, 2917-2932. [CrossRef]

53. Djalante, R.; Holley, C.; Thomalla, F. Adaptive governance and managing resilience to natural hazards. Int. J. Disaster Risk Sci. 2011, 2, 1-14. [CrossRef]

54. Folke, C.; Carpenter, S.; Elmqvist, T.; Gunderson, L.; Holling, C.S.; Walker, B. Resilience and Sustainable Development: Building Adaptive Capacity in a World of Transformations. AMBIO A J. Hum. Environ. 2002, 31, 437-440. [CrossRef] [PubMed]

55. Lebel, L.; Anderies, J.M.; Campbell, B.; Folke, C.; Hatfield-Dodds, S.; Hughes, T.P.; Wilson, J. Governance and the capacity to manage resilience in regional social-ecological systems. Ecol. Soc. 2006, 11, 19. [CrossRef]

56. Olsson, P.; Folke, C.; Berkes, F. Adaptive Comanagement for Building Resilience in Social? Ecol. Syst. Environ. Manag. 2004, 34, 75-90.

57. Ostrom, E. Polycentric systems for coping with collective action and global environmental change. Glob. Environ. Chang. 2010, 20, 550-557. [CrossRef]

58. Corcoran, E.; Nellemann, C.; Baker, E.; Bos, R.; Osborn, D.; Savelli, H. Sick Water: The Central Role of Wastewater Management in Sustainable Development; United Nations Environment Programme and United Nations Human Settlements Programme: Birkeland, Norway, 2010.

59. Cole, D.H. From global to polycentric climate governance. Clim. Law 2011, 2, 395-413. [CrossRef] 
60. Ostrom, E. Governing the Commons: The Evolution of Institutions for Collective Action; Cambridge University Press: Cambridge, UK, 1990; ISBN 0521371015.

61. United Nations General Assembly. Report of the Special Rapporteur on the Human Right to Safe Drinking Water and Sanitation: Participation in the Realization of the Human Rights to Water and Sanitation; Resolution A/69/213; United Nations General Assembly: New York, NY, USA, 2014; p. 25.

62. Jiménez, A.; Livsey, J.; Åhlén, I.; Scharp, C.; Takane, M. Global assessment of accountability in water and sanitation services using GLAAS data. Water Altern. 2018, 11, 238-259.

63. UNDP-SIWI. Water Governance Facility \& UNICEF WASH and Accountability: Explaining the Concept; UNDP Water Governance Facility at SIWI and UNICEF: Stockholm, Sweden; New York, NY, USA, 2015.

64. UNDP-SIWI Water Governance Facility; WIN; Cap-Net; WaterNet. Training Manual on Water Integrity; UNDP-SIWI Water Governance Facility; WIN; Cap-Net; WaterNet: Stockholm, Sweden, 2011.

65. Dekkers, M.; Loutas, N.; De Keyzer, M.; Goedertier, S. Presentation Metadata Open Data \& Metadata Quality. Brussels, Belgium, 2014. Available online: https://www.europeandataportal.eu/sites/default/files/d2.1.2_ training_module_2.2_open_data_quality_en_edp.pdf (accessed on 1 September 2019).

66. Pezij, M.; Augustijn, D.C.M.; Hendriks, D.M.D.; Hulscher, S.J.M.H. The role of evidence-based information in regional operational water management in the Netherlands. Environ. Sci. Policy 2019, 93, 75-82. [CrossRef]

67. Head, B.W. Water policy_Evidence, learning and the governance of uncertainty. Policy Soc. 2010, 29, 171-180. [CrossRef]

68. United Nations. What Is the Rule of Law. Available online: https:/www.un.org/ruleoflaw/what-is-the-ruleof-law/ (accessed on 1 September 2019).

69. United Nations Economic Commission for Europe (UNECE). Convention on the Protection and Use of Transboundary Watercourses and International Lakes (Water Convention); UNECE: Geneva, Switzerland, 1992.

70. United Nations General Assembly. Convention on the Law of the Non-Navigational Uses of International Watercourses; Resolution A/RES/51/229; United Nations General Assembly: New York, NY, USA, 1997.

71. Holling, C.S. Understanding the Complexity of Economic, Ecological, and Social Systems. Ecosystems 2001, 4, 390-405. [CrossRef]

72. Granit, J.; Liss Lymer, B.; Olsen, S.; Tengberg, A.; Nõmmann, S.; Clausen, T.J. A conceptual framework for governing and managing key flows in a source-to-sea continuum. Water Policy 2017, 19, 673-691. [CrossRef]

73. World Commission on Environment and Development (WCED). Brundtland Report: Our Common Future; Oxford University Press: Oxford, UK, 1987.

74. WIN Water Integrity Global Outlook; Water Integrity Nework: Berlin, Germany, 2016; ISBN 9788578110796.

75. Transparency International. The Anti-Corruption Plain Language Guide; Transparency International: Berlin, Germany, 2009.

76. Mosler, H.-J. A systematic approach to behavior change interventions for the water and sanitation sector in developing countries: A conceptual model, a review, and a guideline. Int. J. Environ. Health Res. 2012, 22, 431-449. [CrossRef] [PubMed]

77. Jiménez-Fdez de Palencia, A.; Cortobius, M.; Kjellén, M. Working with Indigenous Peoples in Rural Water and Sanitation: Recommendations for An Intercultural Approach; Stockholm International Water Institute: Stockholm, Sweden, 2014.

78. USAID Water for Africa through Leadership and Institutional Support (WALIS). Available online: https: //www.globalwaters.org/WALIS (accessed on 11 September 2019).

79. Rayner, J.; Williams, H.M.; Lawton, A.; Allinson, C.W. Public Service Ethos: Developing a Generic Measure. J. Public Adm. Res. Theory 2010, 21, 27-51. [CrossRef]

80. Moulaert, F.; MacCallum, D.; Mehmood, A.; Hamdouch, A. The International Handbook on Social Innovation: Collective Action, Social Learning and Transdisciplinary Research. Rev. za Soc. Polit. 2014, 21, 377-381.

81. UNDP Water Governance Facility; UNICEF. WASH Bottleneck Analysis tool: Country Implementation Guide; United Nations Children's Fund: New York, NY, USA, 2019.

82. Berkes, F.; Colding, J.; Folke, C. Building resilience and adaptive capacity in social-ecological systems. In Navigating Social-Ecological Systems: Building Resilience for Complexity and Change; Berkes, F., Colding, J., Folke, C., Eds.; Cambridge University Press: Cambridge, UK, 2002. 
83. Holling, C.S. Resilience and Stability of Ecological Systems. Annu. Rev. Ecol. Syst. 1973, 4, 1-23. [CrossRef]

84. Ostrom, E. A General Framework for Analyzing Sustainability of Social-Ecological Systems. Science 2009, 325, 419-422. [CrossRef] 